\title{
DALL'AGNOL SOBRE WITTGENSTEIN E SEGUIR REGRAS
}

\author{
Eduardo Ferreira das Neves Filho \\ Universidade Federal de Pelotas
}

\section{DALL'AGNOL, D. Seguir regras. Uma introdução às Investigações Filosóficas de Wittgenstein. Pelotas: Ed. UFPel, 2011, 192p.}

No Tractatus Logico-Philosophicus, Wittgenstein adverte que os pensamentos ali expressos possivelmente só sejam entendidos por quem é capaz de pensar por si próprio. Ao mesmo tempo, destaca que as verdades dos respectivos pensamentos são irretocáveis e definitivas, pois resolvem os problemas filosóficos e mostram, ao bom entendedor, que em verdade não é importante resolvê-los. Essas ideias associadas à força perlocucionária do discurso tractariano anunciam um término à Filosofia (a um modo de fazer Filosofia, o que não deixa de ser o caso, em certo sentido), e criam a ilusão de que pouco se tem a fazer depois de Wittgenstein, podendo suscitar certo quietismo filosófico.

É interessante notar que parte dos leitores de Wittgenstein mantém postura quietista mesmo diante da insuficiência das ideias contidas no Tractatus, insuficiência essa reconhecida pelo próprio Wittgenstein, o que o levou a mudar pela segunda vez os rumos da filosofia contemporânea com a organização das Investigações Filosóficas, publicadas postumamente. Manterse em uma perspectiva quietista é, como eu gostaria de colocar a questão, discutir Wittgenstein, seja de que período e respectivo pensamento for, descrevendo os pensamentos desse autor, nada mais, nada menos, em um trabalho de exegese, ou seja, descrever aquilo que parece definitivo, e que pode, no máximo, necessitar de clareamento e organização.

Darlei Dall'Agnol, em seu livro Seguir Regras: Uma introdução às Investigações Filosóficas de Wittgenstein, recentemente publicado na Coleção Dissertatio de Filosofia, (Pelotas, 2011), nos apresenta uma coletânea de doze 
trabalhos que publicou anteriormente. Neles desafia o tipo de quietismo filosófico que destaquei discutindo e esclarecendo bem questões importantes do pensamento de Wittgenstein (algumas vezes buscando pontos de partida às ideias wittgensteinianas, ainda que possamos criticar algumas interpretações que realizou, como é natural), pensando e escrevendo bem com, mas sobretudo a partir de Wittgenstein, servindo-se das reflexões deste filósofo para esclarecer e tentar resolver alguns problemas filosóficos recorrentes, na maior parte dos casos no campo da filosofia moral.

Aquele que se fixar em demasia no título poderá supor que o livro de Dall'Agnol se constitui em um manual, um esclarecimento inicial das Investigações pela via de um problema central que é sempre referido pela fortuna crítica: seguir regras. Não é o caso de que o livro seja introdutório. No livro, o leitor não encontrará primeiros passos para compreender pensamentos de Wittgenstein. As reflexões de Dall'Agnol têm sentido diferente: elas remontam percursos intelectuais decorrentes de uma série de pesquisas que desenvolveu sobre Wittgenstein e que foram reorganizadas (como chama a atenção na Apresentação do livro) para que os trabalhos (já publicados) pudessem ser reunidos em formato de livro. Em todos os capítulos do livro Dall'Agnol revela seu modo de fazer filosofia: trabalhar com 'problemas', e não somente escrever sobre História da Filosofia.

Podemos suspeitar que haja certa dissonância entre o título do livro e o conteúdo de alguns dos capítulos. No entanto, em uma reflexão que realiza com Wittgenstein, tácita ou expressamente o pano de fundo argumentativo de Dall'Agnol (em todos os capítulos) se desenvolve sobre a convicção de que a linguagem é uma atividade guiada por regras, regras gramaticais no sentido profundo (o que não cabe esclarecer aqui), e essa é certamente uma característica marcante em todos os pensamentos do filósofo vienense bem registrados por Dall'Agnol para seus próprios propósitos de pesquisa em filosofia prática, de modo geral, e particular no campo ética.

Tomada desse modo a 'arquitetura' do livro, isto é, tendo como pano de fundo a questão de seguir regras (então por ora resolvida a questão do título), seria compreensível que o subtítulo indicasse ser o livro 'uma introdução às Investigações Filosóficas de Wittgentein, ainda que uma introdução sui generis, isto é, como resultado do percurso intelectual 'wittgensteiniano' de Dall'Agnol e suas observações sobre seguir regras. No entanto, alguns capítulos não tratam diretamente das Investigações Filosóficas, mas estão relacionados ao Tractatus ou a outras obras de Wittgenstein posteriores às Investigações, por exemplo, ao Da 
Certeza, utilizado por Dall'Agnol para tentar dissolver o Paradoxo de Moore, dissolução que pretendo comentar adiante. Por que, então, um subtítulo que nos fala de uma introdução às 'Investigações' tão somente, visto que o problema de seguir regras tem eco na filosofia wittgensteiniana de modo geral?

Dall'Agnol, na Apresentação, diz que o livro presta uma homenagem aos 60 anos de falecimento de Wittgenstein, e pretende fazê-lo discutindo temas de sua filosofia tardia, particularmente temas das Investigações Filosóficas. Isoladamente, essa afirmação não é elucidativa para se compreender o subtítulo, nem tampouco as razões para o compêndio, as quais são elencadas por Dall'Agnol logo a seguir.

Porém, adiante, no primeiro e segundo capítulos, por exemplo, Dall'Agnol mostra-se atento à discussão de como se deve compreender a filosofia de Wittgenstein: ou sustentando-se interpretações que separam realmente "dois" Wittgenstein, o do Tractatus e o das Investigações, ou se devese dar crédito (e a essa posição Dall'Agnol parece estar filiado) àqueles que sustentam ser o conjunto da obra de Wittgenstein uma continuidade. A questão não é rejeitar a existência de diferentes etapas no pensamento de Wittgenstein (inclusive, como se especula recentemente, há quem sustente a hipótese da existência de um 'terceiro' Wittgenstein, identificado nas anotações dos últimos anos de sua vida, particularmente no Da Certeza), mas sustentar que existem fios condutores que estão presentes em todo o percurso intelectual deste autor. Ao mesmo tempo em que identifica essa característica do pensamento wittgensteiniano, as próprias pesquisas de Dall'Agnol (as que estão contidas no livro) se apresentam como uma continuidade, como é observado no final do livro com a tese do cognitivismo prático (construído a partir da assunção do saber-como, importante para o Wittgenstein das Investigações).

Apesar de reconhecer, como fiz acima, que existe certa unidade no livro de Dall'Agnol construída sobre o leitmotiv seguir regras, acredito que seria improdutivo que eu tentasse encontrar uma (s) característica (s) marcante (s) das reflexões de Dall'Agnol que me permitissem dizer o 'quanto' ele defende posições genuinamente wittgensteinianas, ou mesmo o contrário. Isto por vários motivos, entre eles pelo fato de que, como já me ative a dizer anteriormente, Dall'Agnol não tem postura filosófica quietista, pôde pensar com e a partir de Wittgenstein; por não ser natural pensar que exista uma 'escola wittgensteiniana' (e o próprio Wittgenstein tinha ojeriza a ter seguidores, como se comenta); e o que é evidente: pelas várias ideias discutidas que, apesar de envolverem o aspecto de seguir regras, são 
desenvolvidas em diferentes direções, o que necessitaria, por si só, de um exame de doze capítulos de certo modo independentes. Por isso, escolho dois capítulos apenas para apresentar ao leitor. Em ambos Dall'Agnol defende perspectivas originalíssimas. Uma delas me interessa em particular ${ }^{1}$.

Para Dall'Agnol, o tema que está entre os "principais pontos de continuidade no pensamento de Wittgenstein" (p. 12) é o sentido ético das obras de Wittgenstein. Assim, os capítulos em que se discute o Tractatus, particularmente o primeiro - "Sobre aquilo de que não se pode dizer, deve-se falar”-, servem como pontos de partida para sedimentar essa percepção sobre a obra de Wittgenstein.

No primeiro capítulo, Dall'Agnol pretende esclarecer alguns malentendidos correntes em interpretações do Tractatus, particularmente no que diz respeito à introdução do sentido completo da obra por meio de certa 'lei ética' encontrada em seu Prefácio: "o que se pode em geral dizer, pode-se dizer claramente; e sobre aquilo de que não se pode falar, deve-se calar”. No capítulo resume reflexões que realizou e estão publicadas em seu livro "Ética e Linguagem"(nas edições de (1993; 1995 e 2005), bem como foram apresentadas em comunicação no vigésimo sétimo Simpósio Internacional sobre Wittgenstein (2004), com o título "What we cannot say, we can and must speak about".

Levantando a pergunta "sobre o que se deve calar?" (realmente), tenta desfazer o seguinte paradoxo: normalmente a resposta a essa pergunta parece contraditória, visto que o próprio Wittgenstein em TLP 6.421 destaca que as proposições da ética não podem ser colocadas em palavras, mais ainda em TLP 7, onde nos diz que 'Sobre aquilo de que não se pode falar, deve-se calar". Ou seja, o Tractatus parece ter sentido ético, se tomamos como ponto de partida a 'lei ética' contida no Prefácio; e, parece haver uma lei 'ética', ao final, que rejeita a própria ética ou o próprio sentido ético da obra, aparentemente destacado no Prefácio. Deste modo, haveria, além de um paradoxo, uma contradição eminente na obra. Como essa tensão pretende ser resolvida, para Dall 'Agnol?

Retomando a distinção wittgensteiniana entre dizer e mostrar, Dall'Agnol ressalta que os limites daquilo que se pode dizer, de acordo com o Wittgenstein do Tractatus, com sentido, é dado pelo que se pode figurar; todas as sentenças que não podem ser figuradas, não serão nem verdadeiras, nem falsas, não

1 O chamado "Paradoxo de Moore" foi meu tema de investigação na pesquisa de mestrado e de doutorado, esse sob orientação de Darlei Dall'Agnol.. 
corresponderão a nenhum estado de coisas possível. Quando se tenta dizer alguma coisa sem obedecer a 'lei' da representação linguística, constrói-se pseudoproposições. É o caso das proposições da ética, que só podem, a seu turno, ser mostradas e não podem ser ditas. Mas, podemos falar de proposições morais? Sim, é o que sustenta Dall'Agnol. Baseado na distinção entre dizer e mostrar, Dall'Agnol sugere uma distinção entre dizer e falar: Algo é 'dito' quando representa um estado de coisas possível, de acordo com a regra da figuração; algo é falado quando expressa alguma coisa sem cumprir as condições de sentido, ainda que construindo pseudoproposições. E justamente a proibição de falar sobre proposições dessa natureza, como proposições que dizemos morais, não cabe aqui. Elas não podem ser ditas, se dizer é compreendido com pretensões figurativas, mas podem ser faladas, pois pertencem, como Dall'Agnol sustenta, ao domínio do místico, a esfera das coisas que não dizem que o mundo é, mas que ele existe. Podemos, pois, falar do sentido da vida, mesmo que o sentido da vida não se constitua em um fato, não esteja sub judice das condições de verdade aplicadas às proposições empíricas.

O contraste apontado por Dall'Agnol entre juízos morais e éticos é elucidativo. Ambos não são genuínas proposições, não podem ser verdadeiros nem falsos, mas os primeiros são sem sentido, enquanto que os segundos contrasensos, pois tentam dizer aquilo que só pode ser mostrado, carregando uma pretensão, como destaca Dall'Agnol, metafisica. O 'calar-se' proposto por Wittgenstein requer, como compreende o autor do livro Seguir Regras, ser distinguido segundo suas pretensões de verdade: deve-se calar quando não se pode dizer, quando se tem pretensões cientificistas sobre as questões de natureza moral; se não há pretensão de verdade e fundamentação da moral, pode-se falar, e nos mantemos no domínio das expressões comuns da moralidade humana ${ }^{2}$. A implicação da análise faz Dall'Agnol sustentar a tese de que o Wittgenstein do Tractatus, assim, sustenta uma epistemologia moral não-cognitivista.

Conclui Dall'Agnol que o paradoxo apontado acima é só aparente. A tese 7 do Tractatus refere-se a uma proibição às filosofias da moral, não à moralidade cotidiana e seus 'problemas'. Também a aparente contradição é dissipada, visto que Wittgenstein não parece abolir a moralidade, mas tenta limitar o discurso cientificista sobre a moral, realizado em teorias éticas.

\footnotetext{
2 Recentemente, interpretando o Da Certeza, Daniéle Moyal-Sharrock, em Understanding Wittgenstein's On Certainty (New York: Palgrave Macmillan, 2007), discutindo a não-proposicionalidade de algumas proposições, faz exatamente essa distinção, entre dizer e falar, anteriormente apontada por Dall'Agnol.
} 
Assim, o silêncio tractariano diz respeito a um calar-se em sentido lógicofilosófico sobre questões que envolvem a moralidade; não é um calar-se em sentido trivial, devemos falar sobre muitas questões morais, denunciando calúnias, malfeitos de toda a natureza, sob a pena de, caso contrário, assumirmos um silêncio imoraß.

Mas, nem toda a análise de Dall'Agnol sobre seguir regras tem (aparentemente) repercussões imediatas sobre o campo da moral. No décimo primeiro capítulo do livro, propõe-se a esclarecer as regras de uso dos verbos epistêmicos crer e saber, com isso, oferecendo uma dissolução ao Paradoxo de Moore (PM). O que tem de ser explicado é o que há de absurdo em pensamentos e asserções de sentenças tais como a) 'Está chovendo, mas não creio' ou b) 'Está chovendo, mas creio que não está', cuja diferença lógica é ressaltada pela fortuna crítica, inclusive oferecendo-se, em muitos casos, explicações ou soluções diferentes para cada caso. Também, alguns autores tentam explicar por que esse 'paradoxo' acontece apenas qiando o verbo crer é conjugado na primeira pessoa do presente do indicativo, e não acontece quando o crer é conjugado em terceira pessoa, no passado ou no futuro. Dall'Agnol, em sua análise, não discute esse ponto em particular, mas se concentra sobre a 'absurdidade' das sentenças Moore-paradoxais ${ }^{4}$.

Após sintetizar outras tentativas wittgensteinianas de dissolução do PM, a primeira observação importante para compreendermos como Dall'Agnol constrói a argumentação que leva à sua dissolução do PM é a de que o verbo 'saber' teria semelhanças de família, em Wittgenstein, com compreender, entender, cujo uso possível faria com que o austríaco não rejeitasse a definição tradicional de conhecimento para determinado jogo de linguagem (do conhecimento, desse modo compreendendo a importância dessa 'definição' em

\footnotetext{
${ }^{3}$ Chamando a atenção para esse tipo de regra, Dall'Agnol parece abrir terreno à discussão posterior sobre a interpretação de se o 'segundo' Wittgenstein, das Investigações Filosóficas, é cognitivista ou não-cognivista no que diz respeito à ética, o que parece ser sugerido ao final do capítulo e ao final do livro com a proposta do cognitivismo prático, que mencionei acima. Tratar dessa questão com cuidado foge às pretensões de análise aqui. Essa menção, no entanto, é oportuna para se notar que a pesquisa de Dall'Agnol, apesar de tratar de seguir regras em outras obras de Wittgenstein que não nas Investigações, tem o propósito de compreender a filosofia de Wittgenstein como continuidade, discutindo criticamente os resultados das mudanças de perspectiva realizadas pelo autor até a sua morte em 1951, particularmente com reflexos sobre as questões envolvendo a moralidade.

${ }^{4}$ Dall'Agnol apresenta o problema e, após, reconstrói a análise que o PM recebeu de Moore para contrastála com sua dissolução wittgensteiniana do PM, apresentada adiante (Cf. as páginas 153 - 160).
} 
um dado contexto): ter conhecimento é ter crença, verdadeira e justificada ${ }^{5}$. Wittgenstein, em seus últimos escritos, publicados após a sua morte com o título de Da Certeza, exatamente no parágrafo 177 afirma que "aquilo que sei, acredito” (WIIGENSTEIN, Da Certeza, s/d, Lisboa: Edições 70, p. 61). Para Dall'Agnol, essa frase mostra que Wittgenstein estava preocupado em estabelecer as regras desse uso particular do verbo saber, indicando a correta aplicação, em consequência, do verbo crer.

Sentenças Moore-paradoxais seriam absurdas, pois, se "Saber= $\mathrm{df}$ acreditar e ter evidências adequadas que justifiquem a crença; crer= $\mathrm{df}$ ter a pré-disposição de aceitar a verdade de uma proposição mesmo sem evidências suficientes” (p. 165), então o primeiro conjunto seria a manifestação de que 'sei que $p$ ', e, no segundo conjunto, nego ter o conhecimento de $p$, pois nego a crença em $p$ (no caso de 1), ou afirmo a crença no contrário (no caso de 2). Seria correto asserir, por exemplo, 'Creio que está chovendo, embora não o saiba', mas não 'Sei que está chovendo, mas não creio'. Ou seja, tanto no caso de 1 , como no caso de 2, não cumpri corretamente o uso dos verbos crer e saber; assim, "o Absurdo de Moore é simplesmente um mau uso de verbos epistêmicos” (p. 165).

Ora, a dificuldade maior na tentativa de dissolução ao PM oferecida por Dall'Agnol é justamente ter de mostrar que sempre, em uma asserção de sentença Moore-paradoxal, na primeira metade da conjunção há uma alegação de algo forte como conhecimento, ou seja, sempre ao asserir $p$ alguém está asserindo 'eu sei que $p$ ', ainda que o contexto seja apropriado para uma pessoa (pretender) sustentar conhecimento, no sentido tradicional do termo. Sem esse passo, fica permitido imaginar uma série de situações em que as pessoas não alegam 'saber' uma dada proposição, mas apenas possuem crença sobre ela, ainda não têm condições de assegurar o conhecimento de $p$, apesar de sua asserção ocorrer, como já disse, em um cenário 'epistêmico'. E, se esse for o caso, então voltamos ao princípio: ter de explicar a razão da absurdidade de asserções de sentenças Moore-paradoxais ${ }^{6}$. Em uma situação dessas, na ausência de condições para assegurar 'conhecimento' sobre uma dada proposição, ainda que o quisesse, a pessoa descumpriu alguma regra, isso é correto dizer, mas será

${ }^{5}$ De acordo com Dall"Agnol, Wittgenstein "não recusaria completamente a definição tradicional de conhecimento" (p. 164), mas a estaria relacionando a um uso do verbo saber, que tem semelhanças de família com compreender.

${ }^{6} \mathrm{E}$, temos de lembrar que uma pessoa pode duvidar de que saiba sobre $p$ apenas 'pensando', e não asserindo $p$. Desse modo uma solução ao PM deve ser simultânea a um 'pensamento' de proposição Moore-paradoxal e sua respectiva asserção (e a pessoa deve saber as razões pelas quais seu 'pensamento' é incorreto). 
importante dizer qual regra efetivamente ela descumpriu (então, algo mais sobre a lógica da asserção deve ser trazido ao debate).

Caso seja verdade que possamos construir cenários nos quais o PM se dissipa mediante diferentes recursos, por exemplo, em certas asserções que parecem ser 'contradições disfarçadas' (como o fizeram alguns dos autores que defenderam uma posição expressivista, tentando mostrar que sempre a asserção de 'eu creio que $p$ ' é idêntica a asserção pura e simples de $p$ ) - e também aqui, em Dall'Agnol, para o qual o problema deve ser respondido unicamente na esfera de um jogo de linguagem do saber, devemos sempre procurar explicar a situação que nos parece mais espinhosa, e que foge a cenários exclusivos: quando há uma tensão entre as crenças que declaro em primeira pessoa e das quais 'duvido' em terceira pessoa. Aqui está o ninho das vespas menos indolentes de Moore, parafraseando o Wittgenstein de Cultura e Valor ${ }^{7}$.

Como eu disse antes, não analisei o 'quanto' Dall'Agnol é mais ou menos ortodoxo no livro em suas interpretações wittgensteinianas dos problemas discutidos. Parece que no caso de sua dissolução wittgensteiniana do PM, a ortodoxia é o caso. Cabe ao leitor do livro tirar suas próprias conclusões a respeito disso, tanto na leitura desse capítulo, quanto dos demais capítulos nos quais Dall'Agnol se ocupa de outros problemas. Certamente encontrará uma série de investigações que devem ser levadas adiante, pois, como eu mencionei acima, Dall'Agnol desafia qualquer quietismo filosófico e nos faz (re) pensar sobre muitas questões relevantes relativas a seguir regras na filosofia de Wittgenstein.

Recebido em: Novembro de 2011

Aprovado em: Dezembro de 2011

Email: eduardofnfilho@yahoo.com.br

\footnotetext{
7 Por isso, é duvidoso que possamos construir cenários em que asserções de sentenças Mooreparadoxais possam ter sentido e não ser absurdas. Por exemplo, se digo '(Sei que) Minha tia faleceu e não acredito', como afirma Dall'Agnol, inconformado com sua morte. Nesse caso, pois dificilmente estamos em posição de saber a correta intenção de falantes em asserções. O problema está na conjunção. Se eu tivesse dito 'Minha tia faleceu. Não acredito', certamente não haveria aí qualquer absurdidade.
} 